\title{
The effect of Kinesio Tape on scapular kinematics with different external loads in healthy subjects
}

\author{
William Dhein, ${ }^{12}$ Alisson de Carvalho Chaves, ${ }^{3}$ Júlia Araújo Momo, ${ }^{3}$ Natália Miranda Flores, ${ }^{3}$ Matheus Pitrez \\ da Silva Mocellin, ${ }^{3}$ Joelly Mahnic de Toledo, ${ }^{1}$ Jefferson Fagundes Loss. ${ }^{1}$
}

\begin{abstract}
'Universidade Federal do Rio Grande do Sul (UFRGS), Porto Alegre, Rio Grande do Sul, Brasil, ${ }^{2}$ Centro Universitário da Serra Gaúcha (FSG),
\end{abstract} Caxias do Sul, Rio Grande do Sul, Brasil, ${ }^{3}$ Centro Universitário Ritter dos Reis (UNIRITTER), Porto Alegre, Rio Grande do Sul, Brasil.

\begin{abstract}
Background: Alterations of scapular kinematics have been associated with musculoskeletal disorders of the shoulder complex. Objective: Investigate the effects of Kinesio Tape (KT) on scapular kinematics with different external loads in healthy subjects Methods: Twenty-three subjects performed abduction, scaption and flexion of their shoulders in three conditions: (1) no load (2) dumbbell and (3) elastic band resistance. KT was applied (I-shaped) over the upper trapezius muscle, and scapula kinematic data was captured and analyzed based on Euler angles. The situations and interactions of the different loads and KT were compared using a repeated measures two-way ANOVA. KT decreased the upward rotation during the movements of abduction, scaption and flexion of the shoulder. Results: There was an effect of load in all evaluated movements, but there was no interaction between the load and the KT. Conclusion: KT and load showed effects on scapula kinematics. Regardless of the load condition (no load, dumbbell or elastic resistance), the effects of the KT on scapula kinematics will be the same in healthy subjects.

Keywords: Kinesio tape; Shoulder joint; Scapula kinematics.
\end{abstract}

\section{BACKGROUND}

Alterations of scapular kinematics have been associated with musculoskeletal disorders of the shoulder complex. ${ }^{(1)}$ Such alterations, including a decrease in upward rotation, ${ }^{(2-6)}$ less external rotation, ${ }^{(7)}$ less posterior tipping, ${ }^{(8,9)}$ an increase in internal rotation, ${ }^{(4,7,9,10)}$ scapula elevation ${ }^{(11)}$ and protraction 4, are mentioned in shoulder impingement syndrome, rotator cuff tendinopathy and scapular dyskinesis subjects. Due to these alterations and the important role of the scapula on shoulder function 10, the application of Kinesio Tape (KT) over the scapular muscles has been investigated to prevent and rehab scapular alterations. ${ }^{(12,13)}$

Several studies have investigated the effects of KT on scapular kinematic of healthy subjects, ${ }^{(14-16)}$ scapular dyskinesis subjects, ${ }^{(8,13)}$ athletes ${ }^{(17)}$ and patients with shoulder impingement syndrome (SIS). ${ }^{(16,18-20)}$ These studies reached different results for increased upward rotation, $(8,13,15,17)$ posterior tilt,,$(8,13,15,18,19)$ increased retraction and external rotation $^{(21)}$ and no effect on scapula kinematics. $^{(14,16,20,22)}$ Most of the studies investigated the effects of KT during a functional activity or during movements (abduction, scaption and flexion) as part of a rehabilitation program. However, regarding external loads, they were limited to dumbbells. Evaluations were conducted with $2 \mathrm{~kg}$ dumbbells during scaption $19,25 \%$ of maximum force $8,20 \%$ in patients with SIS 20 or 2.3 or $1.4 \mathrm{~kg} 9$. Although it is relevant to evaluate the effects of dumbbell use, it also important to remember that during rehabilitation programs, one of the most important and often used tools to provide external resistance is the elastic band. ${ }^{(23,24)}$

An elastic exercise band is a rubber band ${ }^{(25)}$ of latex or other elastic polymers ${ }^{(24)}$ which allows individualized adjustments through color (representing different levels of resistance), stretch, point of fixation and line of action. ${ }^{(24,26)}$ They are easy to handle and permit patients to perform a slow, controlled exercise targeting the desire muscles. ${ }^{(26-29)}$ The band results in gradual resistance throughout the exercise, reaching maximum resistance at the end of the movement when the band is at its greatest length. The direction of the force is modified according to the execution of the exercise and the point of fixation. Therefore, it does not depend on gravity but is aligned with the orientation of the elastic device, while with a dumbbell the line of action is predominantly vertical. ${ }^{(24,26)}$

Although there are differences in the behavior of the external loads, there is inconsistency in the change of the kinematics produced by the addition of external loads [dumbbell or elastic band] according to shoulder elevation, ${ }^{(27)}$ with an increase ${ }^{(30)}$ and decrease $^{(27)}$ of the different scapula kinematics movements being found. Therefore, knowing how the use of KT associated with different external loads (dumbbell or elastic band) may influence scapula kinematics is important for developing a rehabilitation program. Additionally, if the effects of KT differ according to the load used, this study can help clinicians choose the most appropriate load 
during the different stages of rehabilitation.

Therefore, the aims of the study were: (1) first, investigate the effect of KT on scapular kinematics in healthy subjects during the abduction, scaption and flexion of the shoulder and (2) secondly, determine whether a change in external load (weight load, dumbbell and elastic band) influences the KT effect. Based on the literature, ${ }^{(15,31)}$ our first hypothesis is that KT will increase upward rotation in the evaluated movements, and our second hypothesis is that a change in external load will influence the KT effect.

\section{METHODS \\ Participants}

A sample of 23 healthy men (age, $22.4 \pm$ 2.7 years; mass, $72.2 \pm 6.1 \mathrm{~kg}$; height, $1.8 \pm 0.1$ $\mathrm{m})$ participated in the study. The eligibility criteria of the included subjects were right upper limb dominance, free range of motion and grade 5 muscle strength. Subjects who experienced pain or injury in the last six months, had surgery to the shoulder complex, engaged in physical activity more than three times a week, used shoulder tape in the last 30 days and/or presented positive on the clinical tests were excluded (Jobe, Hawkins and Apprehension). The study was approved by the Ethics Committee of the Universidade Federal do Rio Grande do Sul, under No. 908,977 based on the Declaration of Helsinki. The sample size calculation was performed using $\mathrm{G}^{*}$ Power version 3.1.9.2 software by adopting the following criteria: $5 \%$ probability of error, $0.85 \%$ statistical power and 0.7 effect size. ${ }^{(15)}$

\section{Procedures}

Data acquisition was carried out at Laboratório de Pesquisa do Exercício from Universidade Federal do Rio Grande do Sul and scheduled according to the participants' availability. Each individual signed the informed consent form, and sociodemographic and anthropometric data were obtained during the anamnesis. A physiotherapist evaluated the participants through clinical tests, muscle strength and range of motion.

The kinematics data were captured by the BTS SMART DX 7000 tracking system (ITA) with 10 infrared cameras at a frequency rate of $100 \mathrm{~Hz}$ registering reflective markers. The markers (Figure 1) were positioned over the spinous processes from C7 and T8, suprasternal notch, xiphoid process, acromioclavicular joint, angulus acromialis, processus coracoideus, inferior angle of scapula, trigonum spinae scapulae, medial epicondyle, lateral epicondyle, radial styloid processus and ulnar styloid processus. ${ }^{(32)}$

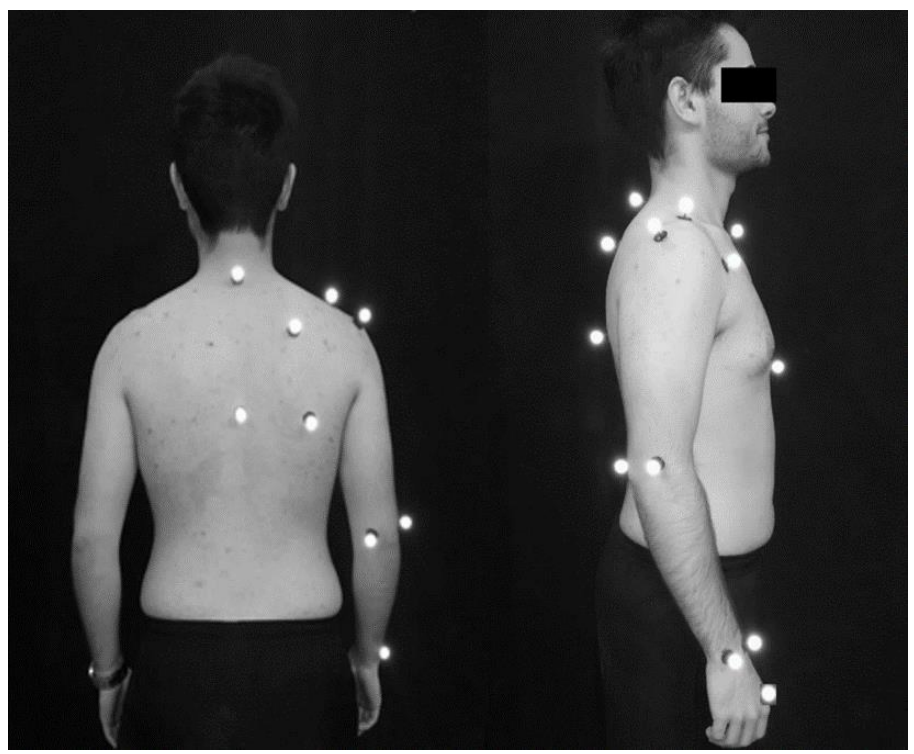

Figure 1. Reflective Markers

The abduction, scaption and flexion of the shoulder were performed in three load situations: (1) active-free movement/no load; (2) dumbbell resistance and (3) elastic band resistance. For each movement, three repetitions were performed with a range of motion of $90^{\circ}$ and a velocity of $45^{\circ}$ per second using a digital metronome. The plane of movement during scaption was $45^{\circ}$ of the scapular plane delimited by nylon threads that provided tactile feedback to the participants. The order of the load was randomized.

The load adjustment for the dumbbell and elastic band exercises corresponded to $5 \%$ of body weight, ${ }^{(33)}$ which was, on average, $3.6 \mathrm{~kg}$. Different dumbbells were used according to the subjects' weight: a) between 50 and $54 \mathrm{~kg}(2.5 \mathrm{~kg}$ dumbbell), b) between 55 and $64 \mathrm{~kg}$ ( $3 \mathrm{~kg}$ dumbbell), c) between 65 and $74 \mathrm{~kg}(3.5 \mathrm{~kg}$ dumbbell), d) between 75 and $84 \mathrm{~kg}(4 \mathrm{~kg}$ dumbbell) and between 85 and $90 \mathrm{~kg}$ (4.5kg dumbbell). For the elastic band exercises, a red color band (Theraband( $\AA$ ) previously calibrated ${ }^{(29)}$ was used as elastic resistance. The band was attached to a load cell (Libracom®) that was positioned at the base of the elastic band and fixed to the floor with a hook. The frequency rate of the load cell was 100hz. During the gesture resisted by the elastic band, the load was reached at the end of range of motion. After the movements, the subjects were led to a stretcher to apply the KT.

The KT (Kinesio Tex Gold®) was placed in 
an I shape over the upper trapezius muscle ${ }^{(34)}$ (Figure 2). Initially, the base of the tape was positioned over the processus coracoideus and stretched until the trigonum spinae. In our study, the distal anchor was changed because the reflective marker was next to the medial border, and thus the anchor was positioned more toward the medial so as not to move the reflective marker. The control of tension applied on the tape was $20 \%$, following an equation adapted from the literature. ${ }^{(20,35)}$ Each application was done by the same physiotherapist. After KT placement, the participant performed the movements of abduction, scaption and flexion of the shoulder in the same conditions previously described with a randomization of the load situations.

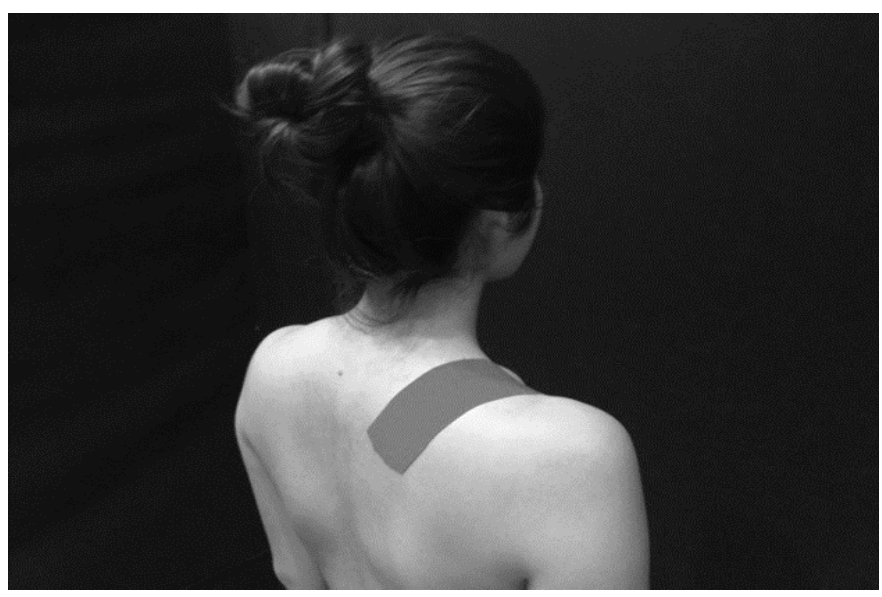

Figure 2. I-shaped tape position

\section{Data analysis}

Kinematic data were analyzed using the BTS Smart-Analyzer software. The kinematic data were digitally filtered using a $4^{\circ}$ order Butterworth lowpass with a frequency of $5 \mathrm{~Hz}$. The articular angles were expressed at Euler angles, ${ }^{(32,36)}$ and the axes were based on the local coordinate system of the bone. The order of rotation of the Euler angles ( $\mathrm{Y}-\mathrm{Z}-\mathrm{X}$ ) was based on the standardization proposed by the International Shoulder Group of the International Society of Biomechanics. ${ }^{(32,36,37)}$ The scapulohumeral (upward/downward rotation, internal/external rotation and posterior/anterior tilt) range of motion during the movements and conditions was selected for statistical analysis.

\section{Statistical analysis}

Statistical analyses was performed using SPSS version 20.0 software. ${ }^{(38)}$ The comparisons of each Euler angle (upward rotation, internal rotation and posterior tilt) in the movements (abduction, flexion and scaption) were performed through a two-way repeated measures ANOVA considering the main factors load (3 levels: no load, dumbbell and elastic band) and KT (2 levels: no KT and KT). The level of significance was $\alpha<0.05$.

\section{RESULTS \\ Abduction of the shoulder}

Regarding the main factors (Table 1 and 2), there was a significant KT effect on upward rotation $\left[F=4.638 ; p=0.042 ;\right.$ eta $\left.^{2}=0.174\right]$, where the use of KT resulted in a decrease of $1.0^{\circ}$ in the range of motion. There was no significant effect of KT on internal rotation $\left[F=0.142 ; p=0.710\right.$; eta $^{2}$ $=0.006]$ and posterior tilt $[F=1.614 ; p=0.217$; eta $\left.^{2}=0.068\right]$. Concerning the main factor load, there was an effect during upward rotation $[\mathrm{F}=$ 4.094; $p=0.023$; eta $^{2}=0.157$ ] between the no load vs. dumbbell load ( $p=0,016)$, where the use of a dumbbell led to an increase of $2.0^{\circ}$ in the range of motion. There was no significant interaction between load $\mathrm{x}$ KT during upward rotation [ $F=0.117 ; p=0.890 ;$ eta $\left.^{2}=0.005\right]$, internal rotation $\left[F=0.599 ; p=0.554 ;\right.$ eta $^{2}=$ 0.027 ] or posterior tilt [F $=0.510 ; p=0.604$; eta ${ }^{2}$ $=0.023$.

\section{Scaption - Elevation on scapular plane}

Regarding the main factors (Tables 1 and 2 ), the KT significantly affected upward rotation [F $=20.563 ; \mathrm{p}<0.001 ;$ eta $\left.^{2}=0.507\right]$, its use producing a decrease of $1.4^{\circ}$ in the range of motion. Concerning load, there was an effect during upward rotation $\left[F=5.398 ; p=0.008\right.$; eta $^{2}$ $=0.213]$, where the use of a dumbbell resulted in an increase of $2.3^{\circ}$ in the range of motion, and internal rotation $\left[F=4.068 ; p=0.025\right.$; eta ${ }^{2}=$ $0.169]$, where the use of an elastic band led to an increase of $1.5^{\circ}$ in the range of motion. No significant interaction was found between load $\mathrm{x}$ KT during upward rotation $[F=0.023 ; p=0.997$; eta $\left.^{2}=0.001\right]$, internal rotation $[F=0.840 ; p=$ 0.439 ; eta $\left.{ }^{2}=0.040\right]$ or posterior tilt $[F=1.654 ; p$ $=0.204 ;$ eta $\left.^{2}=0.076\right]$.

\section{Flexion of the shoulder}

Regarding the main factors (Tables 1 and 2 ), the KT showed a significant effect on upward rotation $\left[F=5.410 ; p=0.031 ;\right.$ eta $^{2}=0.213$, where the use of KT resulted in a decrease of $1.2^{\circ}$ in the range of motion. Concerning load, there was an effect during upward rotation $[F=22.981$; $p<$ 0.001 ; eta $\left.^{2}=0.535\right]$, internal rotation $[F=17.138$; $\mathrm{p}<0.0001 ;$ eta $\left.^{2}=0.461\right]$ and posterior tilt $[\mathrm{F}=$ $5.610 ; p=0.007 ;$ eta $\left.^{2}=0.219\right]$, 
where the use of a dumbbell led to, respectively an increase of $4,5^{\circ}, 2,9^{\circ}$ and $1,0^{\circ}$, an increase of $4.5^{\circ}, 2.9^{\circ}$ and $1.0^{\circ}$ in the range of motion. When comparing no load vs. an elastic band, there was an effect of load during the upward rotation and internal rotation, where the use of an elastic band increased the range of motion by $2.7^{\circ}$ and $2.3^{\circ}$.
No significant interaction was found between load $x$ KT during upward rotation $[F=0.735 ; p=0.486$; eta $\left.^{2}=0.035\right]$, internal rotation $[F=0.013 ; p=$ 0.987 ; eta $\left.{ }^{2}=0.001\right]$ or posterior tilt $[F=0.091 ; p$ $=0.913 ;$ eta $\left.^{2}=0.005\right]$.

Table 1. The main effects of Kinesio Tape on scapula kinematics during abduction, scaption and flexion of the shoulder. The range of motion is described in degrees (standard error).

\begin{tabular}{|c|c|c|c|c|}
\hline 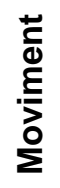 & Rotation of scapula & No KT & KT & $\begin{array}{l}\text { Within factor } \\
\text { difference }\end{array}$ \\
\hline \multirow{3}{*}{$\begin{array}{l}\frac{5}{0} \\
\frac{0}{0} \\
\frac{\partial}{0} \\
\frac{0}{0}\end{array}$} & Upward Rotation & $29.9^{\circ}(0.8)$ & $28.9^{\circ}(0.9)$ & $1.0^{\circ * *}$ \\
\hline & Internal Rotation & $10.1^{\circ}(0.7)$ & $9.9^{\circ}(0.6)$ & $0.2^{\circ}$ \\
\hline & Posterior Tilt & $6.9^{\circ}(0.4)$ & $6.1^{\circ}(0.6)$ & $0.7^{\circ}$ \\
\hline \multirow{3}{*}{$\begin{array}{l}\text { 을 } \\
\text { 응 } \\
\text { હ }\end{array}$} & Upward Rotation & $27.0^{\circ}(0.8)$ & $25.6^{\circ}(0.9)$ & $1.3^{o *}$ \\
\hline & Internal Rotation & $10.1^{\circ}(0.6)$ & $10.2^{\circ}(0.8)$ & $0.1^{\circ}$ \\
\hline & Posterior Tilt & $5.64^{\circ}(0.2)$ & $5.67^{\circ}(0.3)$ & $0.0^{\circ}$ \\
\hline \multirow{3}{*}{$\begin{array}{l}\frac{\sigma}{x} \\
\frac{0}{4}\end{array}$} & Upward Rotation & $23.9^{\circ}(0.8)$ & $22.7^{\circ}(0.7)$ & $1.2^{\underline{0} *}$ \\
\hline & Internal Rotation & $14.1^{\circ}(0.7)$ & $14.4^{\circ}(0.7)$ & $0.3^{\circ}$ \\
\hline & Posterior Tilt & $6.5^{\circ}(0.4)$ & $6.8^{\circ}(0.3)$ & 0.3 \\
\hline
\end{tabular}

Table 2. The main effects of load on scapula kinematics during abduction, scaption and flexion of the shoulder. The range of motion is described in degrees (standard error).

\begin{tabular}{|c|c|c|c|c|c|c|c|}
\hline 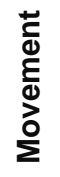 & $\begin{array}{c}\text { Rotation } \\
\text { of } \\
\text { scapula }\end{array}$ & No Load (1) & $\begin{array}{c}\text { Dumbbell } \\
(2)\end{array}$ & $\begin{array}{c}\text { Elastic Band } \\
\text { (3) }\end{array}$ & $\begin{array}{l}\text { Within factor } \\
\text { difference } \\
\text { (1 vs. 2) }\end{array}$ & $\begin{array}{l}\text { Within factor } \\
\text { difference } \\
\text { (1 vs. 3) }\end{array}$ & $\begin{array}{c}\text { Within } \\
\text { factor } \\
\text { difference } \\
\text { (2 vs. } 3 \text { ) }\end{array}$ \\
\hline \multirow{3}{*}{ 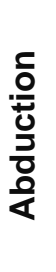 } & $\begin{array}{l}\text { Upward } \\
\text { Rotation }\end{array}$ & $28.5^{\circ}(0.7)$ & $30.5^{\circ}(0.9)$ & $29.3^{\circ}(0.9)$ & $2.0^{\circ * *}$ & $0.7^{\circ}$ & $1.2^{\circ}$ \\
\hline & $\begin{array}{l}\text { Internal } \\
\text { Rotation }\end{array}$ & $10.4^{\circ}(0.7)$ & $9.6^{\circ}(0.5)$ & $9.9^{\circ}(0.7)$ & $0.7^{\circ}$ & $0.4^{\circ}$ & $0.3^{\circ}$ \\
\hline & $\begin{array}{c}\text { Posterior } \\
\text { Tilt }\end{array}$ & $6.8^{\circ}(0.4)$ & $6.9^{\circ}(0.4)$ & $5.9^{\circ}(0.7)$ & $0.1^{\circ}$ & $0.9^{\circ}$ & $1.0^{\circ}$ \\
\hline \multirow{3}{*}{ 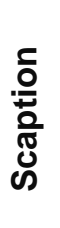 } & $\begin{array}{l}\text { Upward } \\
\text { Rotation }\end{array}$ & $24.9^{\circ}(1.0)$ & $27.3^{\circ}(1.1)$ & $26.7^{\circ}(0.7)$ & $2.3^{\circ * *}$ & $1.7^{\circ}$ & $0.6^{\circ}$ \\
\hline & $\begin{array}{l}\text { Internal } \\
\text { Rotation }\end{array}$ & $9.4^{\circ}(0.8)$ & $10.3^{\circ}(0.5)$ & $10.9^{\circ}(0.8)$ & $0.8^{\circ}$ & $1.5^{\circ} \neq$ & $0.6^{\circ}$ \\
\hline & $\begin{array}{c}\text { Posterior } \\
\text { Tilt }\end{array}$ & $5.5^{\circ}(0.2)$ & $5.9^{\circ}(0.4)$ & $5.5^{\circ}(0.3)$ & $0.3^{\circ}$ & $0.0^{\circ}$ & $0.4^{\circ}$ \\
\hline
\end{tabular}




\begin{tabular}{|c|c|c|c|c|c|c|}
\hline \multirow{3}{*}{ 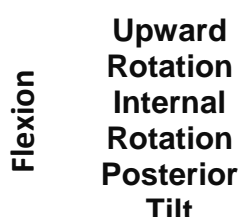 } & $20.9^{\circ}(0.8)$ & $25.4^{\circ}(0.8)$ & $23.6^{\circ}(0.8)$ & $4.5^{0 *}$ & $2.7^{\circ} \neq$ & $1.8^{\circ}$ \\
\hline & $12.5^{\circ}(0.6)$ & $15.4^{\circ}(0.8)$ & $14.8^{\circ}(0.8)$ & $2.9^{\circ *}$ & $2.3^{\circ} \neq$ & $0.6^{\circ}$ \\
\hline & $6.3^{\circ}(0.4)$ & $7.3^{\circ}(0.3)$ & $6.4^{\circ}(0.4)$ & $1.0^{*}$ & 0.4 & 0.9 \\
\hline
\end{tabular}

*Note: *Significant difference between no load and dumbbell $(p<0.05)$; significant difference between no load and elastic band $(p<0.05)$.

\section{DISCUSSION}

The aims of the study were to investigate the effect of KT on scapular kinematics in healthy subjects during abduction, scaption and flexion of the shoulder and whether a change in external load (no load, dumbbell and elastic band) influenced the KT effect. Our results reject our first hypothesis and found the opposite, suggesting that KT over the upper trapezius decreased the upward rotation of the evaluated movements. Concerning the interaction between load $x \mathrm{KT}$, our results reject the second hypothesis, indicating that there was no interaction between the factors and suggesting that the KT effect on the range of motion during upward rotation, internal rotation and posterior tilt rotation is the same, regardless of the load condition.

The literature reports results showing that KT increases upward rotation, ${ }^{(8,13,15,17)}$ posterior tilt, $, 8,13,15,18,19)$ retraction and external rotation 21, but has no effect on scapula kinematics. ${ }^{(14,16,20,22)}$ Therefore, our results differ with those found the literature. The change of scapular kinematics with KT may be connected to a new recruitment of the periscapular muscles' motor units, ${ }^{(10)}$ the characteristics of the sample or a 900 range of motion. According to the literature, studies found that when the Ishaped KT was applied over the upper trapezius, there was a decrease in electromyography activity. ${ }^{(39-41)}$ The same results were found with subjects with suspected SIS, ${ }^{(41)}$ rotator cuff tendinopathy ${ }^{(17)}$ and scapular dyskinesis. ${ }^{(8)}$ If we consider our sample of healthy subjects, who a priori don't have an alteration of scapula kinematics and EMG, we may expect a decrease in EMG activity of the upper trapezius, and therefore less contribution of the muscle in the upward rotation.

Another explanation may be related with our range of motion extending until $90^{\circ}$, where the upper trapezius has less contribution compared to the lower trapezius, ${ }^{(7,42)}$ and with this decrease in EMG activity less upward rotation occurred during this range of motion.
However, as we did not evaluate EMG activity in this study, we cannot validate this hypothesis. Moreover, it is important to emphasize that we do not know if this change, just $1.0^{\circ}-1.3^{\circ}$ of upward rotation in abduction, scaption and flexion, would be clinically relevant. Therefore, future studies should evaluate EMG activity with a kinematics evaluation in randomized clinical trials.

Regarding the load conditions, a greater upward rotation was found with the use of a dumbbell compared to no load during the evaluated movements. These results agree with those previously reported in the literature, which also revealed an increase in the upward rotation during abduction ${ }^{(30,43)}$ and anteflexion. ${ }^{(43)}$ For internal/external rotation during flexion without load, a lesser range of motion was determined, but no difference was seen on the upward rotation of the scapular dyskinesis subjects. ${ }^{(8)}$ When comparing an elastic band with no load movements, a greater upward rotation on flexion and internal rotation during scaption and flexion were found, which disagrees with another study. ${ }^{(27)}$ This was probably due to the load adjustments being different and the manner in which the elastic band was attached to the floor. Nonetheless, there was no interaction between load x KT; hence, the effects of the KT are the same regardless of the load condition.

Therefore, in clinical practice, whether the subjects use a dumbbell or an elastic band during the evaluated movements associated with the $\mathrm{KT}$, the effects on their scapula kinematics will be the same, making the choice of which load to use dependent on the patient's evaluations. We need to remember that our results cannot be extrapolated to subjects with shoulder injuries since the sample comprised healthy subjects. Moreover, we cannot ensure that this change will be clinically relevant. Future studies should explore different magnitudes of load (in our study, load was defined as 5\% of body weight) and subjects with shoulder pathologies to verify if the interaction between KT $x$ load remains the same. 
There are limitations and perspectives when considering the results. First, we found a decrease in upward rotation with the use of $\mathrm{KT}$, but the evaluated movements extended until $90^{\circ}$ degrees. Therefore, futures studies should evaluate different ranges of motion and verify if this behavior continues past $90^{\circ}$. The choice to delimit the movement to this range of motion is justified by the markers attached to the scapula, which may not follow the behavior of the bone because of the skin they are attached to. Despite that, there was a control in the plane of motion in the form of nylon threads. Another limitation is that the EMG activity of the scapular muscles was not evaluated. Future studies should evaluate these muscles to sustain the scapula kinematic results and the hypothesis of the decrease in the EMG activity of the upper trapezius and consequently the downward rotation found in the study. We need to highlight in our study the control of the tension applied to the tape (control by equation), the different loads and the analysis of the interaction between the factors load and $\mathrm{KT}$, which may help to improve the current knowledge concerning KT effects.

\section{CONCLUSION}

Kinesio Tape decreased the upward rotation during the movements of abduction, scaption and flexion of the shoulder. There was no interaction between load $x \mathrm{KT}$, suggesting that the KT effects on scapular kinematics are the same, regardless of the load condition (no load, dumbbell or elastic resistance) in healthy subjects.

Authors' contributions: WD, ASC, JAM, NMF and MPSM were responsible for the development of the study, collection of kinematic data, data analysis, statistics and writing of the manuscript. JMT and JFL are the study coordinators. All authors approved the final manuscript and there was no conflict of interest.

Financial support: Nothing to declare.

Conflict of interest: Nothing to declare.

\section{REFERENCES}

1. Ou H-L, Huang T-S, Chen Y-T, Chen W-Y, Chang Y-L, Lu T-W, et al. Alterations of scapular kinematics and associated muscle activation specific to symptomatic dyskinesis type after conscious control. Manual Therapy. 2016;26:97103. doi:10.1016/j.math.2016.07.013.

2. Ludewig PM, Braman JP. Shoulder impingement: biomechanical considerations in rehabilitation. Manual Therapy. 2011;16(1):339. doi:10.1016/j.math.2010.08.004.

3. Ludewig PM, Reynolds JF. The association of scapular kinematics and glenohumeral joint pathologies. journal of orthopaedic \& sports physical therapy. 2009;39(2):90-104. doi:10.2519/jospt.2009.2808.

4. Kibler WB, Sciascia A. The role of the scapula in preventing and treating shoulder instability. Knee Surgery, Sports Traumatology, Arthroscopy. 2016;24(2):390-7. doi:10.1007/s00167-015-3736-z.

5. Leong HT, Ng GY-f, Chan SC, Fu SN. Rotator cuff tendinopathy alters the muscle activity onset and kinematics of scapula. Journal of Electromyography and Kinesiology. 2017;35:406. doi:10.1016/j.jelekin.2017.05.009.

6. Lawrence RL, Braman JP, LaPrade RF, Ludewig PM. Comparison of 3-dimensional shoulder complex kinematics in individuals with and without shoulder pain, part 1: sternoclavicular, acromioclavicular, and scapulothoracic joints. journal of orthopaedic \& sports physical therapy. 2014;44(9):636-45. doi:10.2519/jospt.2014.5339.

7. Lopes AD, Timmons MK, Grover M, Ciconelli RM, Michener LA. Visual scapular dyskinesis: kinematics and muscle activity alterations in patients with subacromial impingement syndrome. Archives of physical medicine and rehabilitation. 2015;96(2):298-306. doi:10.1016/j.apmr.2014.09.029.

8. Tooth C, Schwartz C, Colman D, Croisier J-L, Bornheim S, Brüls $O$, et al. Kinesiotaping for scapular dyskinesis: The influence on scapular kinematics and on the activity of scapular stabilizing muscles. Journal of Electromyography and Kinesiology. 2020;51:102400. 10.1016/j.jelekin.2020.102400.

9. Huang T-S, Ou H-L, Huang C-Y, Lin J-J. Specific kinematics and associated muscle activation in individuals with scapular dyskinesis. Journal of Shoulder and Elbow Surgery. 2015;24(8):122734. doi:10.1016/j.jse.2014.12.022.

10. Castelein B, Cagnie B, Parlevliet T, Cools A. Scapulothoracic muscle activity during elevation exercises measured with surface and fine wire EMG: a comparative study between patients with subacromial impingement syndrome and healthy controls. Manual Therapy. 2016;23:339. doi:10.1016/j.math.2016.03.007.

11. Lin J-j, Hanten WP, Olson SL, Roddey TS, Sotoquijano DA, Lim HK, et al. Functional activity characteristics of individuals with shoulder dysfunctions. Journal of Electromyography and 
Kinesiology.

$2005 ; 15(6): 576-86$ doi:10.1016/j.jelekin.2005.01.006.

12. Thelen MD, Dauber JA, Stoneman PD. The clinical efficacy of kinesio tape for shoulder pain: A randomized, double-blinded, clinical trial. Journal of Orthopaedic and Sports Physical Therapy. doi:10.2519/jospt.2008.2791.

13. Huang T-S, Ou H-L, Lin J-J. Effects of trapezius kinesio taping on scapular kinematics and associated muscular activation in subjects with scapular dyskinesis. Journal of Hand Therapy. 2019;32(3):345-52. doi:10.1016/j.jht.2017.10.012.

14. Zanca GG, Grüninger B, Mattiello SM. Effects of Kinesio taping on scapular kinematics of overhead athletes following muscle fatigue. Journal of Electromyography and Kinesiology. 2016;29:113-20. doi:10.1016/j.jelekin.2015.06.005.

15. Van Herzeele M, Van Cingel R, Maenhout A, De Mey K, Cools A. Does the application of kinesiotape change scapular kinematics in healthy female handball players? International Journal of Sports Medicine. 2013;34(11):950-5. doi:10.1055/s-0033-1334911.

16. Keenan KA, Akins JS, Varnell M, Abt J, Lovalekar M, Lephart S, et al. Kinesiology taping does not alter shoulder strength, shoulder proprioception, or scapular kinematics in healthy, physically active subjects and subjects with Subacromial Impingement Syndrome. Physical Therapy in Sport. 2016. doi:10.1016/j.ptsp.2016.06.006.

17. Leong HT, Ng GY-f, Fu SN. Effects of scapular taping on the activity onset of scapular muscles and the scapular kinematics in volleyball players with rotator cuff tendinopathy. Journal of Science and Medicine in Sport. 2016. doi:10.1016/j.jsams.2016.10.013.

18. Shih Y-F, Lee Y-F, Chen W-Y. Effects of Kinesiology Taping on Scapular Reposition Accuracy, Kinematics, and Muscle Activity in Athletes With Shoulder Impingement Syndrome: A Randomized Controlled Study. Journal of sport rehabilitation. 2018;27(6):560-9. doi:10.1123/jsr.2017-0043.

19. Hsu YH, Chen WY, Lin HC, Wang WT, Shih YF. The effects of taping on scapular kinematics and muscle performance in baseball players with shoulder impingement syndrome. Journal of Electromyography and Kinesiology. 2009;19(6):1092-9. doi:10.1016/j.jelekin.2008.11.003.

20. Dhein W, Neto ESW, Miranda IF, Pinto AB, Moraes LR, Loss JF. Effects of Kinesio Taping on scapular kinematics and electromyographic activity in subjects with shoulder impingement syndrome. Journal of bodywork and movement therapies.

doi:10.1016/j.jbmt.2019.10.007.

21. Shaheen AF, Bull AM, Alexander CM. Rigid and Elastic taping changes scapular kinematics and pain in subjects with shoulder impingement syndrome; an experimental study. Journal of Electromyography and Kinesiology. 2015;25(1):84-92. doi:10.1016/j.jelekin.2014.07.011.

22. Ozer ST, Karabay D, Yesilyaprak SS. Taping to improve scapular dyskinesis, scapular upward rotation, and pectoralis minor length in overhead athletes. Journal of athletic training. 2018;53(11):1063-70. doi:10.4085/1062-6050342-17.

23. Kuhn JE. Exercise in the treatment of rotator cuff impingement: a systematic review and a synthesized evidence-based rehabilitation protocol. Journal of Shoulder and Elbow Surgery. 2009;18(1):138-60. doi:10.1016/j.jse.2008.06.004

24. Mascarin NC, de Lira CAB, Vancini $R L$, de Castro Pochini A, da Silva AC, dos Santos Andrade $M$. Strength training using elastic bands: Improvement of muscle power and throwing performance in young female handball players. Journal of sport rehabilitation. 2017;26(3):245-52. doi:10.1123/jsr.2015-0153.

25. Kim T-W, An D-I, Lee H-Y, Jeong H-Y, Kim D-H, Sung $\mathrm{Y}-\mathrm{H}$. Effects of elastic band exercise on subjects with rounded shoulder posture and forward head posture. Journal of physical therapy science. 2016;28(6):1733-7. doi:10.1589/jpts.28.1733.

26. Hintermeister RA, Lange GW, Schultheis JM, Bey MJ, Hawkins RJ. Electromyographic activity and applied load during shoulder rehabilitation exercises using elastic resistance. The American journal of sports medicine. 1998;26(2):210-20. doi:10.1177/03635465980260021001.

27. Camci E, Duzgun I, Hayran M, Baltaci G, Karaduman A. Scapular kinematics during shoulder elevation performed with and without elastic resistance in men without shoulder pathologies. journal of orthopaedic \& sports physical therapy. 2013;43(10):735-43. doi:10.2519/jospt.2013.4466.

28. Broilo C, Schuster RC, Dhein W. Electromyographic analysis of muscles of the shoulder complex during external rotation exercises with elastic band. Fisioterapia e 
Pesquisa.

2019;26(3):329-36. doi:10.1590/1809-2950/19004126032019.

29. Loss JF, Koetz AP, Soares DP, Scarrone FF, Hennemann V, Sacharuk VZ. Quantificação da resistência oferecida por bandas elásticas. Revista Brasileira de Ciências do Esporte. 2002;24(1).

Url:http://revista.cbce.org.br/index.php/RBCE/ar ticle/viewFile/340/296

30. Forte FC, de Castro MP, de Toledo JM, Ribeiro DC, Loss JF. Scapular kinematics and scapulohumeral rhythm during resisted shoulder abduction-Implications for clinical practice. Physical Therapy in Sport. 2009;10(3):105-11. doi:10.1016/j.ptsp.2009.05.005.

31. Yildiz TI, Castelein B, Harput G, Duzgun I, Cools A. Does scapular corrective taping alter periscapular muscle activity and 3-dimensional scapular kinematics? A systematic review. Journal of Hand Therapy. 2019. doi:10.1016/j.jht.2019.03.001.

32. Wu G, Van Der Helm FCT, Veeger HEJ, Makhsous M, Van Roy P, Anglin C, et al. ISB recommendation on definitions of joint coordinate systems of various joints for the reporting of human joint motion - Part II: Shoulder, elbow, wrist and hand. Journal of Biomechanics. 2005;38(5):981-92. doi:10.1016/j.jbiomech.2004.05.042.

33. de Toledo JM, Ribeiro DC, de Castro MP, Forte FC, Körbes TS, Rusch MW, et al. Comparison of shoulder resultant net moment between three different exercises and load conditions. Physiotherapy theory and practice. 2013;29(2):124-32.

doi:10.3109/09593985.2012.699606.

34. Morrissey D. Proprioceptive shoulder taping. Journal of bodywork and movement therapies. 2000;4(3):189-94. doi:https://doi.org/10.1054/jbmt.2000.0156.

35. Magalhães I, Bottaro M, Freitas JR, Carmo J, Matheus JP, Carregaro RL. Prolonged use of Kinesiotaping does not enhance functional performance and joint proprioception in healthy young males: Randomized controlled trial. Brazilian journal of physical therapy. 2016.doi:10.1590/bjpt-rbf.2014.0151.

36. Meskers C, Vermeulen H, De Groot J, Van der Helm F, Rozing P. 3D shoulder position measurements using a six-degree-of-freedom electromagnetic tracking device. Clinical biomechanics. 1998;13(4-5):280-92. doi:10.1016/S0268-0033(98)00095-3.

37. Doorenbosch CA, Harlaar J, Veeger DH. The globe system: an unambiguous description of shoulder positions in daily life movements.
Journal of rehabilitation research and development. 2003;40(2):147.

38. Field AP, Miles J, Field Z. Discovering statistics using R/Andy Field, Jeremy Miles, Zoë Field. London; Thousand Oaks, Calif.: Sage; 2012,

39. Lin Jj, Hung CJ, Yang PL. The effects of scapular taping on electromyographic muscle activity and proprioception feedback in healthy shoulders. Journal of Orthopaedic Research. 2011;29(1):53-7. doi:10.1002/jor.21146.

40. Takasaki H, Delbridge BM, Johnston V. Taping across the upper trapezius muscle reduces activity during a standardized typing task-An assessor-blinded randomized cross-over study. Journal of Electromyography and Kinesiology. 2015;25(1):115-20. doi:10.1016/j.jelekin.2014.10.004.

41. Selkowitz DM, Chaney C, Stuckey SJ, Vlad G. The effects of scapular taping on the surface electromyographic signal amplitude of shoulder girdle muscles during upper extremity elevation in individuals with suspected shoulder impingement syndrome. Journal of Orthopaedic \& Sports Physical Therapy. 2007;37(11):694702. doi:10.2519/jospt.2007.2467.

42. Diederichsen LP, Norregaard J, Dyhre-Poulsen P, Winther A, Tufekovic G, Bandholm T, et al. The activity pattern of shoulder muscles in subjects with and without subacromial impingement. Journal of Electromyography and Kinesiology. 2009;19(5):789-99. doi:10.1016/j.jelekin.2008.08.006.

43. Pascoal AG, van der Helm FF, Correia PP, Carita I. Effects of different arm external loads on the scapulo-humeral rhythm. Clinical biomechanics. 2000;15:S21-S4. doi:10.1016/s0268-0033(00)00055-3. 